\title{
Gastrointestinal Stent Uygulamalarl: Tek Merkez Deneyimi
}

\author{
( (iD) Uzm. Dr. Mustafa Zanyar Akkuzu ${ }^{1}$, @ (iD) Prof. Dr. Orhan Sezgin ${ }^{1}$, @ (iD) Prof. Dr. Fehmi Ateş ${ }^{1}$, \\ @ (iD) Doç. Dr. Osman Özdoğan ${ }^{1}$, @ (iD) Doç. Dr. Serkan Yaraş ${ }^{1}$, @ (iD) Uzm. Dr. Ferzan Aydın", \\ @ (iD) Uzm. Dr. Hatice Rızaoğlu Balcı ${ }^{1}$, @ (iD) Doç. Dr. Enver Üçbilek ${ }^{1}$ @ (iD) Prof. Dr. Engin Altıntaş ${ }^{1}$
}

${ }^{1}$ Mersin Üniversitesi Tıp Fakültesi Gastroenteroloji Bilim Dalı, Mersin, Türkiye

$\ddot{0} z$

Gastrointestinal Stent Uygulamaları: Tek Merkez Deneyimi

Amaç: Gastrointestinal (Gi) stentler gastrointestinal kanaldaki malign veya benign darlıklarda ve akciğer kanseri gibi komșu organ maligniteleri ile ilișkili bası veya fistüllerde ya da operasyonlardan sonraki darlık veya kaçaklarda palyatif amaçla kullanılmaktadır. Bu çalışmada taktığımız Gi stentlerin takılma nedenlerini ve seyrini değerlendirerek Gi stentlerle ilgili klinik deneyimimizi paylașmayı amaçladık.

Materyal ve Metod: 2014-2019 yılları arasında kliniğimizde çeșitli nedenlerle Gi stent takılan olgular çalıșmaya dâhil edilmiștir. Retrospektif olarak stent takılma nedeni, stent çeșidi, komplikasyon olup olmaması, komplikasyonların yönetimi ve hastaların yașam süreleri incelendi. Özellikle ileri evre kanserlerde stentlerin palyatif tedavide etkinliği ve yaşam süresine katkısı değerlendirildi.

Bulgular: Bu süreçte toplam 36 hastaya Gi stent takılmıștı. Hastalarımızın 24 (\%67)'ü erkek ve 12 (\%33)'si kadındı. Erkeklerin yaş

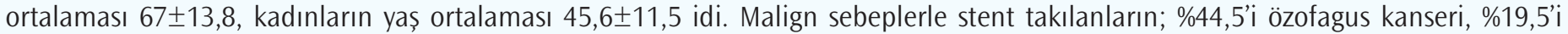
mide kanseri, \%16,6'sında akciğer kanseri ve \%5,5’una da rektum kanseri nedeniyle stent takılmıștı. Benign nedenlerle stent takılanların \%11,1'ine fistül, \%2,8’ine de evre d özofajit nedeniyle stent takılmıștı. Hepsine SEMS takılmıștı. Hastalarımızın \%27'si halen yaşamaktaydı. Hastalarımızın \%73’ü ölmüş olup ortalama yaşam süresine baktığımızda 109,6£101 gün olarak saptadık.

Tartıșma ve Sonuç: Sonuç olarak, ameliyat edilemeyen sindirim sistemi darlığı olan hastaların palyasyonunda stent kullanımının kısa dönemde kaliteli bir palyasyon için etkin bir yöntem olduğu görülmektedir. Kendiliğinden genișleyen metal stentler kullanılarak malign ve benign disfajinin hafiflemesi sağlanabilir.

Anahtar Kelimeler: Gastrointestinal stentler, Kendiliğinden genișleyen stentler, Palyatif destek

\section{Abstract}

\section{Gastrointestinal Stent Applications: Single Center Experience}

Objective: Gastrointestinal (GI) stents are used for palliative purposes in malignant or benign strictures in the gastrointestinal tract and pressure or fistulas associated with neighboring organ malignancies such as lung cancer, or stenosis or leakage after operations. In this study, we aimed to share our clinical experience with GI stents by evaluating the reasons and course of GI stents.

Materials and Methods: Patients who had a Gl stent in our clinic between 2014 and 2019 were included in the study. Retrospectively, the reason for stent insertion, the type of stent, the presence or absence of complications, the management of the complications and the life span of the patients were analyzed. Especially in advanced stage cancers, the effectiveness of stents in palliative treatment and their contribution to life span were evaluated.

Results: During this period, a total of 36 patients had GI stents implanted. 24 (67\%) of our patients were male and 12 (33\%) were female. The mean age of men was $67 \pm 13.8$, and the mean age of women was $45.6 \pm 11.5$. Those who are stented for malign reasons; A stent was implanted for $44.5 \%$ esophageal cancer, 19.5\% stomach cancer, $16.6 \%$ lung cancer and 5.5\% rectal cancer. Of those who were stented for benign reasons, $11.1 \%$ had a fistula, and $2.8 \%$ had a stent due to stage $d$ esophagitis. SEMS was attached to all of them. $27 \%$ of our patients were still alive. $73 \%$ of our patients died and when we looked at the average life span, we found it as $109.6 \pm 101$ days.

Conclusion: As a result, it is seen that the use of stents in palliation of patients with inoperable digestive system stenosis is an effective method for a quality palliation in the short term. By using self-expanding metal stents, malignant and benign dysphagia can be alleviated. Keywords: Gastrointestinal stents, Self-expanding stents, Palliative support 


\section{GíRis}

Gastrointestinal (Gi) stentlerinin kullanımı, Gi kanalın endoskopik olarak ulașılabilen tüm malign veya benign darlıklarında kalıcı veya geçici açıklığı sağlamak için, akciğer kanseri gibi komşu organ malignitelerinden kaynaklanan darlık veya fistülleri tedavi etmek için kullanılmaktadır. Gi operasyonlardan sonraki darlıklarda veya kaçaklarda da kullanımı artmaktadır. Gastrointestinal stentler en sık olarak, cerrahinin uygun olmadığı özofagus kanserli hastalarda, malign disfajinin palyasyonunda kullanılmaktadır (1). Kendiliğinden genișleyebilen metalik stentler ilk kez Domschke ve ark (2) tarafından 1990 yılında malign özofajiyal striktürün kaplı olmayan genișleyebilen metalik stent ile başarılı tedavisi ile bașlamıștır.

Özellikle son yıllarda kaplı ve kaplı olmayan metalik ve plastik stentler malign veya benign sindirim sistemi darlıkların palyasyonunun tedavisinde ilk sırayı almıștır. Genișleyebilen metalik stentler rijit plastik stentlere göre daha pahalı olmasına rağmen daha az sıklıkta komplikasyonlara yol açmaktadır. Bu nedenle komplikasyonlar düșünüldüğünde daha ucuza gelmektedir. Prospektif randomize bir çalışmada lazer ile rekanalizasyonla kıyaslandığında genișleyebilen stentlerin semptomları düzeltmede daha üstün olduğu ve tekrarlayan müdahale ihtiyacını azalttığı görülmüștür (3). Kendiliğinden genișleyebilen metalik stentlerin geliștirilmesi ile sindirim sistemi darlıklarının palyasyonunda oldukça ilerlemeler kaydedilmiștir. Rijit tüplerden avantajları yerleștirme cihazının dar olması, önceden dilatasyon yapılmasına gerek olmaması ve hafif sedasyonla endoskopi veya floroskopi rehberliğinde yerleștirilebilmesidir (4). Stentler \%95 oranında bașarı ile yerleștirilebilmekte olup ișleme bağlı mortalite oranı \%1,5'ten daha azdır (5). Bu çalıșmada; gastrointestinal stentlerin takılma nedenlerini, ișlem bașarısı veya komplikasyonları, yașam sürelerini değerlendirerek Gi stentler ile ilgili klinik deneyimimizin paylașılması amaçlanmıştır.

\section{MATERYAL VE METOT}

2014-2019 yılları arasında, Mersin üniversitesi Tıp Fakültesi Hastanesinde çeșitli nedenlerle Gi stent takılan olgular çalıșmaya dâhil edildi. Retrospektif olarak hastalara ait klinikopatolojik özellikler, yaş, cinsiyet, stent takma endikasyonu, stent çeşidi, işleme bağlı komplikasyon olup olmaması, komplikasyonların yönetimi ve hastaların takip sonuçları ve yașam süreleri hastane dosya sisteminden ve endoskopi raporlarından çıkarıldı. Özellikle ileri evre kanserlerde stentlerin palyatif tedavide etkinliği ve yaşam süresine katkısı değerlendirildi. Bu çalıșma sadece SEMS'leri içermekte olup rijit plastik stentleri içermemiștir.

Gi stent takma tekniği olarak: tüm hastalarda önce endoskopik gözlem altında lezyon saptanıp, darlığın veya lezyonun bașlangıç kısmı ve bitiş kısmı endoskopi ve radyoskopi eșliğinde içine opak madde çekilmiş enjektör veya metalik bir cis- min (iğne vs.) hastanın cildine yapıștırılarak ișaretlenmesi ile lezyon sahasının tespiti ile bașlanmıștı. Gi lümen tama yakın tıkandığında ise tümörlerde distaline geçmek olanaksızdır. Bu aşamada bir kılavuz tel endoskopik görüntü ve radyoskopik kontrol altında tümör distaline gönderilmiști. Daha sonra endoskop çıkarılıp kılavuz tel üzerinden SEMS lezyonu tam ortalayacak ve tümörün proksimalinde $3-4 \mathrm{~cm}$ ve distalinde 3 cm kalacak șekilde serbestleștirilip SEMS yerleștirilmiști. Stentin açıldığı ekranda görüldükten sonra, stenti tașıyan şaft ve kılavuz tel geri çekilip hem radyoskopik hem de endoskop ile stentin açılmış hali ve lokalizasyonu değerlendirilmiști. İșlem sonrası göğüs röntgenogramı ile iyatrojenik pnömotoraks varlığı araștırılmıștı. İșlemden 4 saat sonra hastalara sulu gıda bașlandı ve 24 saat sonra yumușak gıdaya geçilmiști. Tüm hastalar olası aspirasyonu engelemek amaçlı baș kısmı kaldırılarak yatırılmıştı. Rektum kanserinde ise kolonoskopik gözlem altında darlığı geçen kılavuz tel gönderildikten sonra SEMS yerleștirilmiști.

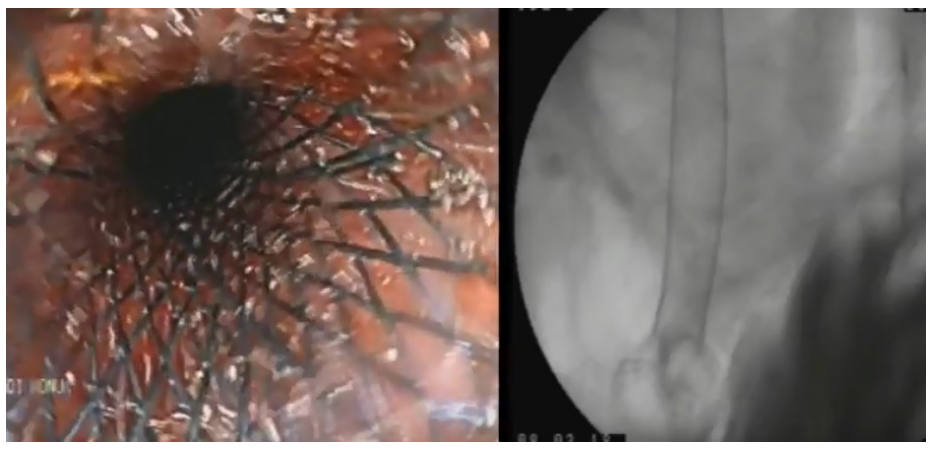

Resim 1. Özofagus kanseri olan hastada açIImış SEMS'in endoskopik ve radyoskopik görünümü

\section{İstatistiksel analiz}

Istatistiksel analizlerin hesaplanmasında SPSS 21.0 for Windows programı kullanıldı. Çalıșma verileri değerlendirilirken tanımlayıcı istatistiksel metodlar (Ortalama, Standart sapma) kullanıldı.

\section{BULGULAR}

Bu sürede toplam 36 olguya Gi stent takılmıștı. Hastalarımızın toplamda 24 (\%67)'ü erkek ve 12 (\%33)'si kadındı. Erkeklerin yaş ortalaması $67 \pm 13,8$, kadınların da yaş ortalaması $45,6 \pm 11,5$ idi.

Malign sebeplerle stent takılanların 21'i erkek ve 10'u kadın olup yaş ortalamaları $59 \pm 14,8$ idi. Hastalarımızın \%44,5’inde özofagus kanseri nedeniyle palyatif amaçlı olarak, \%19,5'inde mide kanseri operasyonu sonrası gelişen darlık nedeniyle, \%16,6'sında akciğer kanseri nedeniyle özofagusa olan dıștan bası, infiltrasyon ve fistül nedeniyle ve \%5, $5^{\prime}$ ine de rektum kanseri nedeniyle stent takılmıştı. Bunların \%74,2'si ölmüş olup \%25,8'i halen yașamaktaydı.

Benign nedenlerle stent takılanların üçü erkek ve ikisi 
kadın hasta olup yaș ortalamaları 50,3 \pm 35 idi. Bu hastalarımızın \%8,3'üne obezite cerrahisi sonrası olușmuş fistül, \%2,8'ine entübasyon sonrası olușmuş iyatrojenik fistül nedeniyle, \%2,8'ine de evre d özofajit nedeniyle stent takılmıștı. Bunların üçü yașamakta olup benign özofagiyal darlığı olan ve entübasyon sonrası iyatrojenik fistülü olan hastalar bașka nedenlerle ölmüștü.

Toplam 10 (\%27) hasta halen yașamaktaydı. Yașayanların

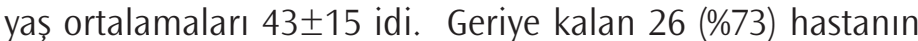

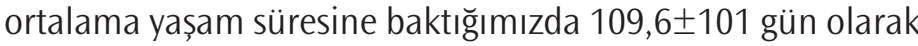
saptadık. Bu hastaların 10 (\%27)'unun yașam süresi 1 ayın altındaydı.

Tablo 1. Stent Takilan Hastaların Özellikleri

\begin{tabular}{|c|c|c|c|}
\hline \multicolumn{2}{|l|}{ Parametreler } & Sayı (N) & Yüzde (\%) \\
\hline \multirow{2}{*}{ Cinsiyet } & Erkek & 24 & 68 \\
\hline & Kadın & 12 & 32 \\
\hline \multirow{6}{*}{$\begin{array}{l}\text { Stent takılma } \\
\text { nedenleri }\end{array}$} & Özofagus kanseri & 16 & 44,5 \\
\hline & Mide kanseri & 7 & 19,5 \\
\hline & Akciğer kanseri & 6 & 16,6 \\
\hline & Özofagial Fistül & 4 & 11,1 \\
\hline & Rektum kanseri & 2 & 5,5 \\
\hline & $\begin{array}{l}\text { Benign özofagiyal } \\
\text { darlık, özofajit }\end{array}$ & 1 & 2,8 \\
\hline \multirow{2}{*}{$\begin{array}{l}\text { Takılan stent } \\
\text { çeșidi }\end{array}$} & Tam Kaplı & 32 & 89 \\
\hline & Kapsız & 4 & 11 \\
\hline \multirow{4}{*}{ Yaşam süreleri } & Yașayan & 10 & 27 \\
\hline & $\begin{array}{l}1 \text { aydan kısa sürede } \\
\text { ölen }\end{array}$ & 10 & 27 \\
\hline & Toplam ölen & 26 & 73 \\
\hline & $\begin{array}{l}\text { Ölenlerin ortalama } \\
\text { yașam süreleri }\end{array}$ & \multicolumn{2}{|c|}{$109,6 \pm 101$ gün } \\
\hline
\end{tabular}

İsleme bağlı komplikasyonlar; özofagus kanseri olan hastalarımızdan birinde stent takılma esnasında perforasyon gelișmiș olup hasta cerrahiye verilmiști ve sonrasında düzelmiști. Üçünde de takiplerinde stent gömülmüștü ve stent çıkarılıp revize edilmiști. Mide kanseri olan hastaların stent takılması esnasında herhangi bir komplikasyon gelișmemiş olup stent takılmış olan üç hastanın takiplerinde stent kayması olmuş ve bunlarda revizyon gerekmiști. Akciğer kanseri olan iki hastada da trakea ve özofagus arasında fistül mevcuttu ve stent sonrası kapanmıștı. Rektum kanserinden dolayı stent takılan hastalarımızda herhangi bir komplikasyon gelişmemiști. İki hastaya obezite cerrahisi sonrası ve iki hastada da bașka nedenlerle entübasyon sonrası iyatrojenik gelișmiş fistül nedeniyle stent takılmıştı. Bu hastaların birinin takiple- rinde stent migrasyonu olmuş olup stent revizyonu yapılmıștı ve her dört hastanın da takiplerinde fistülleri kapanıp stentleri çıkarılmıștı. Geriye kalan bir hastamıza da evre d özofajit nedeniyle olan benign darlık nedeniyle takılmıștı ve takiplerinde herhangi bir problem gelișmemiști.

Hastalarımızın dört (\%11)'üne kapsız stent takılmış olup otuz ikisi (\%89)'ne tam kaplı metalik stent takılmıștı. Hastalara tam kaplı kendiliğinden genleșebilen stentler, $20 \mathrm{~mm}$ çapında 6-12 cm uzunluğunda olanlar uygulanmıștı. Kapsız stentler de $20 \mathrm{~mm}$ çapında ve 8-10 cm uzunluğundaydı. Kapsız stent takılanların üçü erkek biri kadın olup yaș ortalamaları 64 idi. Bunların ikisi özofagus kanseri olan hastalara, biri rektum kanseri olan hastaya ve biri de akciğer kanseri olup özofagusa infiltrasyonu olan hastaya takılmıștı.

\section{TARTIȘMA VE SONUÇ}

Özofagusta endoprotezlerin kullanılmaya bașlanmasından itibaren geçen 150 yılda basit bir borudan kendiliğinden genișleyebilen metal-plastik stentlere kadar gelișme yașanmıștır. Bu gelișmeye paralel olarak da stentlerin kullanım alanları giderek genişlemektedir.

Kanserlerde, kitle ameliyat edilebilir așamada ise cerrahi tercih edilen tedavi yöntemidir. Cerrahi yapılamayan hastalarda tedavi yönetimi palyatif tedaviyle sınırlıdır. Palyatif tedavinin amacı sindirim sistemi açıkığını korumak, katı gıdaların geçișini sağlamak ve ağrıyı azaltmaktır. Günümüzde stentlerin en sık takılma nedeni cerrahinin uygun olmadığı özofagus kanserli hastalardır. Kendiliğinden genișleyen kaplı metal stent özellikle anastomoz kaçaklarında, trakeoözefageal fistüllerde, malign ve benign darlıklarda da kullanılmaktadır (6). Hastalarımızın \%44,5'i özofagus kanseri nedeniyle palyatif amaçlı olarak, \%19,5'i mide kanseri operasyonu sonrası gelișen darlık nedeniyle, \%16,6'sinde akciğer kanseri nedeniyle özofagusa olan dıștan bası, infiltrasyon ve fistülden dolayı, \%11,1'i obezite cerrahisi ve entübasyon sonrası olușmuş iyatrojenik fistül nedeniyle, \%5,5’i rektum kanseri nedeniyle, ve \%2,7'üne de evre d özofajit nedeniyle stent takılmıștı.

Stentin açılması sırasında özofagus duvarına uyguladığı gerilim gücü her tarafta eșittir. Dolayısıyla stent sonrası göğüs ağrısı, reflü șikayetleri stentlerin mekanik etkisiyle reaktif hiperplazi ve fibrozis gelișmesiyle proksimal ve distal darlık, trakeoözefageal fistül gelișimi ve stent migrasyonu gibi komplikasyonlar görülebilmektedir $(7,8)$. Kaplı olmayan stentlerde migrasyon oranı düșük (\%0-3) olup, stent kardiaya yerleștirildiğinde insidans \%6’ya kadar yükselmektedir $(9,10)$. Kaplanmış stentlerin avantajı tümörün büyümesine karșı direnç göstermeleridir, ancak özellikle tam olarak kaplandıklarında daha yüksek bir migrasyon oranına sahiptirler (11). KapIı stentlerde özellikle kardiaya yerleștirildiğinde migrasyon oranı \%25-32 olarak bildirilmektedir $(10,12,13)$. Migrasyonun sebepleri stentin yeterince ekspanse olamaması, kemotera- 
pi veya radyoterapi nedeni ile tümörün küçülmesi, stentin malpozisyonu, stent yerleștirilmeden önce stenozun fazla dilate edilmesi veya özofajiyal peristaltizmin katkısı nedeniyle olabilir. Bizim hastalarımızın dördünde takiplerinde stent migrasyonu olmuș olup revize edilmiștir. Üçünde de takiplerinde stent gömülmüștü ve stent çıkarılıp revize edilmiști. Bir $(\% 2,7)$ hastamızda da stent takılması esnasında özofagus perforasyonu gelișmiș olup hasta cerrahiye verilmiști. Sonuç olarak stent yerleștirilmesi sonrası görülen sekonder striktürlerin açılması için yeniden müdahale gerekebilmektedir.

Metalik stentler kaplı veya kapsız olabilir. Çelik veya nitinol içerebilir. Açıldıklarında çapları 2,5 cm'ye kadar olabilir. En sık tipleri nitinol Ultraflex stent, Wallstent ve Gianturco Z stent'tir (14). Kaplı stentlerin avantajı tümörün içe doğru büyümesine dirençli olmalarıdır. Bununla beraber kaplı stentler daha az stabil olma eğilimindedir. Kaplı olmayan stentlerde ise migrasyon eğilimi daha azdır. Fakat tümörün içe doğru büyümesi ve buna bağlı obstruksiyon riski tașımaktadır (5). Olgularımızda kullanılan stentlerin \%11'i kapsız olup 3\%89'u kaplı stentti. Kaplı ve kapsız stentler Neo tech marka vasküler olmayan kendiliğinden genişleyen stentlerdi.

Özellikle özofajiyal fistülün tedavisinde en iyi sonuçlar yine kaplı bir stent yerleștirilmesidir. Kaplı stent ile özofagorespiratuar fistül vakalarının \%67-100'ünde fistülün tamamen kapandığı görülmüștür $(15,16,17)$. Bizim hastalarımızın ikisinde obezite cerrahisi sonrası, ikisinde entübasyon sonrası iyatrojenik gelișen fistül ve ikisinde akciğer kanseri nedeniyle fistül gelișmiști ve stentleme sonrası \%100'ünde fistülün kapandığı görülmüștü.

Malignitelerin neden olduğu disfajinin palyatif tedavisi için bir yöntem seçerken, neoplastik hastalığın evresi yani kısaca ortalama yașam süresi dikkate alınmalıdır. Yașam süresi 3 ayın üzerinde olan hastaların stentler için endikasyonunun olduğunu düșünmekteyiz. Çalıșmamızda hastalarımızın \%27'sinin ortalama yașam süresi 1 ayın altındaydı ve tüm

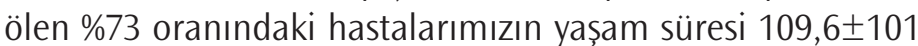
gündü. Dolayısıyla stent takılması öncesinde komplikasyonlarda göz önüne alınarak hastanın yașam beklentisinin dikkate alınması gerektiği görülmektedir. Özellikle erken evrede olan malignitelere ve benign darlıklar nedeniyle stent uygulanan \%27 oranındaki hasta halen yașamakta idi. Yașayanların yaş ortalamaları $43 \pm 15$ idi.

Sonuç olarak, ameliyat edilemeyen sindirim sistemi darı̆̆ nın, mortalitesinin olmaması ve sınırlı morbiditesi ile kısa dönemde kaliteli bir palyasyon için etkin bir yöntem olduğu görülmektedir. Kendiliğinden genișleyen metal stentler kullanılarak malign ve benign disfajinin hafiflemesi sağlanabilir.

\section{BILDIRIMLER}

Değerlendirme

İç danışmanlık

Çıkar Çatıșması

Yazarlar bu makale ile ilgili herhangi bir çıkar çatıșması bildirmemișlerdir.

Finansal Destek

Yazarlar bu makale ile ilgili herhangi bir malî destek kullanımı bildirmemișlerdir.

\section{Etik Beyan}

$\mathrm{Bu}$ için Mersin Üniversitesi Klinik Araștırmalar Etik Kurulundan 22.01.2020 tarih ve 53 Karar No ile etik onay alınmış olup çalıșmanın yürütülmesi sırasında Helsinki Bildirgesi kriterleri göz önünde bulundurulmuştur.

\section{KAYNAKLAR}

1. Lambert R. An overview of the management of cancer of the esophagus. Gastrointest Endosc Clin N Am 1998; 8: 415-34. https://doi.org/10.1016/S1052-5157(18)30270-8

2. Domschke W, Foerster EC, Matek W, Rodl W. Self-expanding mesh stent for esophageal cancer stenosis. Endoscopy 1990; 22: 134-136. https://doi.org/10.1055/s-2007-1012818

3. Giral A, Kalaycı C. Özofagusun kanser dıșı hastalıklarında cerrahi tedavi. In Yüksel $\mathrm{M}$, Başoğlu A. ed. Özofagus Hastalıklarının Tıbbi ve Cerrahi Tedavisi. 2002: 309-320.

4. Tan BS, Mason RC, Adam A. Minimally invasive therapy for advanced oesophageal malignancy. Clin Radiol 1996; 51: 828836. https://doi.org/10.1016/S0009-9260(96)80078-X

5. Eroglu A, Turkyılmaz A, Aydın Y. Özofagus hastalıklarında stent uygulamaları. Turkiye Klinikleri J Thor Surg-Special Topics 2009; 2: 95-99.

6. Radecke K, Gerken G, Treichel U. Impact of a self-expanding, plastic esophageal stent on various esophageal stenoses, fistulas, and leakages: a single-center experience in 39 patients. Gastrointest Endosc 2005; 61: 812-8. https://doi. org/10.1016/S0016-5107(05)00290-7

7. Sandha GS, Marcon NE. Expandable metal stents for benign esophageal obstruction. Gastrointest Endosc Clin North Am 1999; 9: 437-46. https://doi.org/10.1016/S10525157(18)30187-9

8. Boulis NM, Armstrong WS, Chandler WF, et al. Epidural abscess: A delayed complication of esophageal stenting for benign stricture. Ann Thorac Surg 1999; 68: 568-70. https:// doi.org/10.1016/S0003-4975(99)00591-3

9. Adam A, Ellul J, Watkinson AF, et al. Palliation of inoperable esophageal carcinoma: A prospective randomised trial of laser therapy and stent placement. Radiology 1997; 202: 344348. https://doi.org/10.1148/radiology.202.2.9015054

10. Cwikiel W, Tranberg KG, Cwikiel M, et al. Malignant dysphagia: Palliation with oesophageal stents-long term results in 100 patients. Radiology 1998; 207: 513-518. https://doi. 
org/10.1148/radiology.207.2.9577503

11. Sharma P, Kozarek R, Practice Parameters Committee of American College of Gastroenterology. Role of esophageal stents in benign and malignant diseases. Am J Gastroenterol 2010; 105:258. https://doi.org/10.1038/ajg.2009.684

12. Wang MQ, Sze DY, Wang ZP, et al. Delayed complications after esophageal stent placement for treatment of malignant esophageal obstructions and esophagorespiratory fistulas. J Vasc Interv Radiol. 2001; 12: 465-474. https://doi.org/10.1016/ S1051-0443(07)61886-7

13. Kocher M, Dlouhy M, Neoral C, et al. Esophageal stent with antireflux valve for tumors involving the cardia: work in progress. J Vasc Interv Radiol 1998; 9: 1007-1010. https://doi. org/10.1016/S1051-0443(98)70441-5

14. Watkinson A, Ellul J, Entwisle K, et al. Oesophageal carcinoma: initial results with covered self expanding endoprostheses. Radiology 1995;195:821-827. https://doi.org/10.1148/ radiology.195.3.7538682

15. Turkyilmaz, A, Eroglu A, Aydin Y, et al. Complications of metallic stent placement in malignant esophageal stricture and their management. Surg Laparosc Endosc Percutan Tech. 2010; 20; 10-15. https://doi.org/10.1097/SLE.0b013e3181cdebf4

16. Homann N, Noftz MR, Klingenberg-Noftz RD, et al. Delayed complications after placement of self-expanding stents in malignant esophageal obstruction: treatment strategies and survival rate. Dig Dis Sci. 2008; 53: 334- 340. https://doi. org/10.1007/s10620-007-9862-9

17. Shimi SM. Self-expanding metallic stents in the management of advanced esophageal cancer: a review. Semin Laparosc. Surg. 2000; 7: 9-21. https://doi.org/10.1177/155335060000700103 